\title{
ANÁLISE MULTITEMPORAL COM ÍNDICES DE VEGETAÇÃO (NDVI E EVI) DO \\ MUNICÍPIO DE SÃO LUÍS - MA
}

\section{Admo Ramos Silva Júnior'; Clenya Carla Leandro de Oliveira²; Messias Galvão Abreu³; Juliane Borralho de Andrade 4 .}

\begin{abstract}
${ }^{1}$ Graduando em Engenharia Agronômica, Universidade Estadual do Maranhão (UEMA), São Luís, Maranhão, ${ }^{2}$ Graduanda em Engenharia Agronômica, Universidade Estadual do Maranhão (UEMA), São Luís, Maranhão, ${ }^{3}$ Graduando em Engenharia Agronômica, Universidade Estadual do Maranhão (UEMA), São Luís, Maranhão, ${ }^{4}$ Professora Doutora, Universidade Estadual do Maranhão (UEMA), São Luís, Maranhão.
\end{abstract}

DOI: $10.47094 / I C O N N E C A .2021 / 13$

\section{RESUMO}

O Sensoriamento Remoto apresenta dados consistentes da superfície terrestre, principalmente para o monitoramento de recursos naturais. Este trabalho tem como objetivo averiguar possíveis modificações na cobertura vegetal nos anos de 1984, 2001 e 2019, utilizando NDVI e EVI. A área de estudo é o município do São Luís, Maranhão. Foram utilizadas as imagens de satélites Landsat TM 5 e Landsat OLI/TIRS 8, obtidas no período de baixa incidência pluviométrica. Para a data de 1984 o NDVI variou com pixels de 0.00605 até 0.526 e EVI com pixels de -0.296 a 0.771 , na data de 2001 para o NDVI com pixels de -0.081 até 0.453 e EVI com pixels de -0.0287 até 0.26 , na data de 2019 para o NDVI com pixels de 0.052 até 0.524 e EVI com pixels 0.0587 até 0.958 . Houve modificação na vegetação ao longo dos anos, sendo mais perceptível na região norte e central do município.

PALAVRAS-CHAVE: Sensoriamento. Modificações. Landsat.

ÁREA TEMÁTICA: Geoprocessamento e tecnologia digital nas ciências agrárias.

\section{INTRODUÇÃO}

Os recursos naturais da Terra e suas propriedades se favorece do Sensoriamento Remoto, a fim de adquirir informações sobre sua detecção espacial, descrição, quantificação e monitoramento (KIMM et al., 2020; AREKHI et al., 2019). Os sistemas de SR providencia dados consistentes e periódicos da superfície terrestre sendo um mecanismo fundamental no monitoramento local, regional e/ou global tornando-se uma das fundamentais ferramentas utilizadas para compreender os desenvolvimentos dinâmicos inerentes às diversas formas ecossistêmicas (MERCIER et al., 2020; GHOLIZADEH et al., 2018). Dentre as técnicas de processamentos de imagens partir da correção atmosférica devido a interferência de alguns gases, obtidas por SR têm-se os índices de vegetação (IVs), gerando a examinação das propriedades espectrais da vegetação, a partir do comportamento da 
sua reflectância nas bandas dessas imagens como a do visível, do vermelho, infravermelho próximo e do azul com aplicações para o monitoramento da cobertura vegetal e organização dessas superfícies (YANG et al., 2018; BECK, 2006). Portanto o objetivo do presente trabalho é investigar possíveis modificações no cenário da cobertura vegetal no município de São Luís, Maranhão, utilizando os índices de vegetação (IVs): NDVI e EVI, numa série temporal dos satélites TM - Landsat 5 e OLI Landsat 8, nos anos de 1984, 2001 e 2019.

\section{METODOLOGIA}

A área de estudo é o município do São Luís, Maranhão, a área está situada na Mesorregião Norte Maranhense. Sua localização se dá através coordenadas geográficas de $02^{\circ} 24^{\prime} 27^{\prime \prime}$ e 2²9'32" de Lat. Sul; $44^{\circ} 15^{\prime} 48^{\prime \prime}$ e $44^{\circ} 17^{\prime} 41^{\prime \prime}$ de Long. Oeste. O município de São Luís está situado no bioma Amazônia.

Os materiais utilizados foram as imagens de satélites Landsat TM 5 e Landsat OLI/TIRS 8 As imagens foram obtidas para o período de baixa incidência pluviométrica da região de estudo, que compreende as datas de 20/06/1984, 22/10/2001 e 04/05/2019, com resoluções espaciais de 30 metros.

A metodologia iniciou-se através do processamento digital das imagens com a conversão de radiância para reflectância e a correção atmosférica através do método de subtração de objetos escuros DOS (Dark Object Subtraction; CHAVEZ, 1988), aplicada para os dados de reflectância no topo da atmosfera (TOA), para os cálculos dos índices foram utilizados as seguintes equações: Para o NDVI $=N I R-R E D / N I R+R E D$, para o EVI $=\square(\square(\square \square \square \square)-\square(\square \square \square \square)) /(\square \square+\square 1 \square(\square \square \square \square)+$ $\square 2 \square(\square \square \square \square \square)+\square(\square \square \square \square)$ ).

\section{RESULTADOS E DISCUSSÕES}

Com o auxílio da tecnologia dos sensores remotos e das imagens de satélites foi possível analisar a distribuição espacial da cobertura vegetal em São Luís e suas modificações ao longo dos anos analisados de acordo com a Figura 1 que representa a data de 1984 o NDVI com pixels de 0.00605 até 0.526 e EVI com pixels de -0.296 a 0.771 , na data de 2001 para o NDVI com pixels de -0.081 até 0.453 e EVI com pixels de -0.0287 até 0.26 , na data de 2019 para o NDVI com pixels de 0.052 até 0.524 e EVI com pixels 0.0587 até 0.958 .

Os valores do EVI e NDVI variam de $-1 \mathrm{a}+1$, os valores próximos a +1 indicam uma grande quantidade de cobertura vegetal densa. Entretanto, -1 seria o valor aproximado para a ausência da vegetação, em que representa superfícies não vegetadas. Logo, explica-se que esse índice tenha apresentado bons resultados na geração do mapa temático da cobertura vegetal do munícipio de São Luís-MA para os anos de 1984, 2001 e 2019, uma vez que o NDVI gerado se aproximou de 0.5 para os 3 anos e o EVI variando de -0.2 a 0.9 . 
Figura 1: Variabilidade temporal e espacial do EVI e NDVI do município de São Luís - MA.
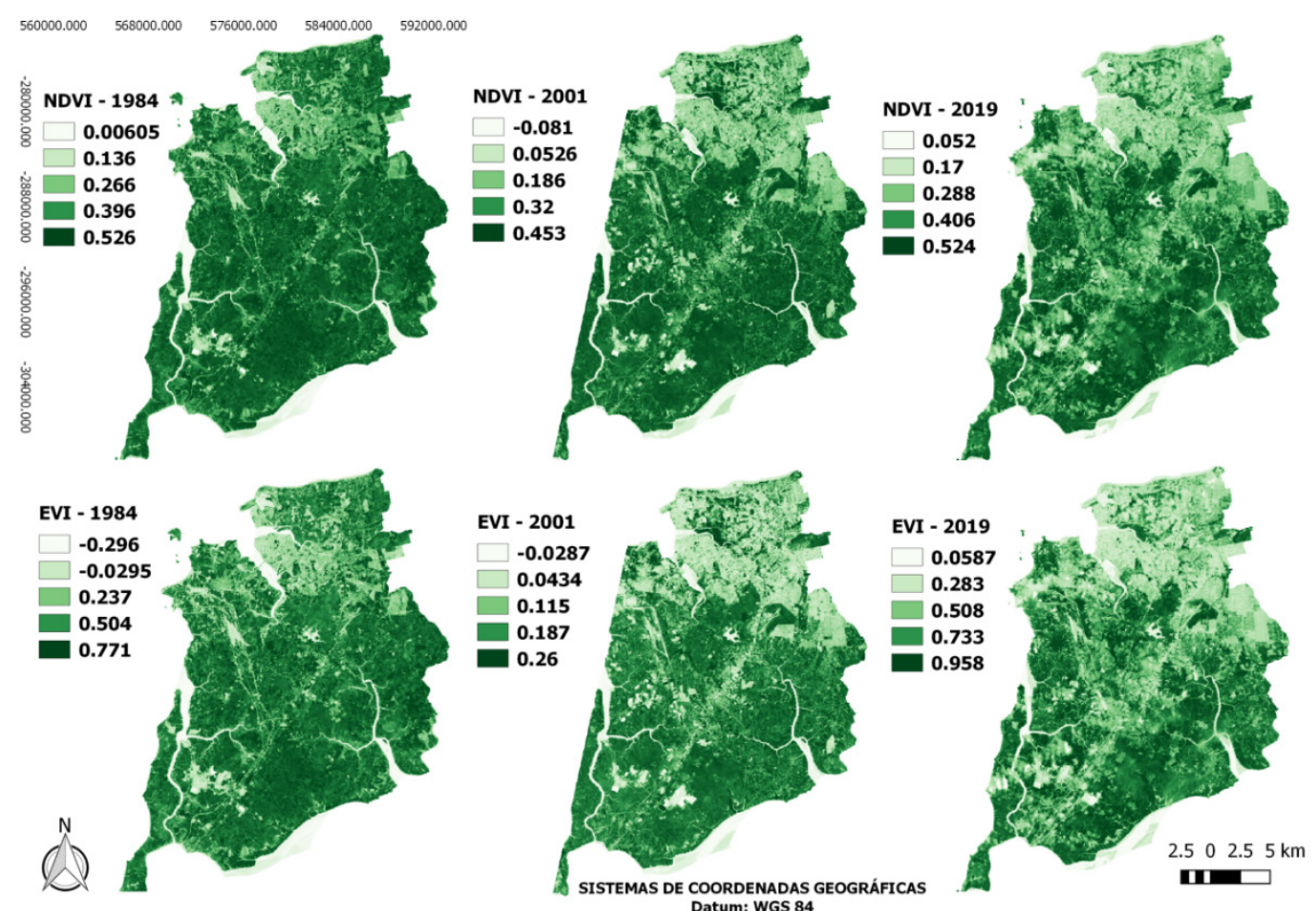

Fonte: Silva Júnior, 2021

\section{CONCLUSÃO}

O padrão de modificação sofrida na vegetação aos longos dos anos analisados foi nítido a partir das análises dos IVs através das imagens de satélites, com isso os dois índices se complementam. As modificações se concentram na parte mais ao norte do município e na parte mais central. Portanto o produto gerado deste trabalho serve como um indicador e para se ter resultados mais expressivos, necessita-se de outros parâmetros.

\section{PRINCIPAIS REFERÊNCIAS}

AREKHI, M.; GOKSEL, C.; SANLI, F. B.; SENEL, G. Comparative Evaluation of the Spectral and Spatial Consistency of Sentinel-2 and Landsat-8 OLI Data for Igneada Longos Forest. ISPRS International Journal Of Geo-information, [s.1.], v. 8, n. 2, p. 56-73, 28 Jan 2019. DOI. 10.3390/ ijgi8020056.

BECK, P.S.A., ATZBERGER, C., HOGDA, K.A., JOHANSEN, B., SKIDMORE, A.K. Improved monitoring of vegetation dynamics at very high latitudes: a new method using MODIS NDVI. Remote Sensing Environ, [s.1.], V. 100, n.3, p.321-334, Feb 2006. DOI. 10.1016/j.rse.2005.10.021.

GHOLIZADEH, A.; ŽIŽALAA, D.; SABERIOON, M.; BORŏVKA, L. Soil organic carbon and 
texture retrieving and mapping using proximal, airborne and Sentinel-2 spectral imaging. Remote Sensing of Environment, [s.1.], v. 218, p. 89-103, Dec 2018. DOI. 10.1016/j.rse.2018.09.015.

CHAVEZ JR., P.S. An improved dark-object subtraction technique for atmospheric scattering correction of multispectral data. Remote Sensing of Environment, [s.1.], v.24, n.3, p. 459- 479, Apr 1988. DOI. 10.1016/0034-4257(88)90019-3.

KIMM, H.; GUAN, K.; JIANG, C.; PENG, B.; GENTRY, L. F.; WILKIN, SCOTT C.; WANG, S.; CAI, Y.; BERNACCHI, C. J.; PENG, JIAN. Deriving high-spatiotemporal-resolution leaf area index for agroecosystems in the U.S. Corn Belt using Planet Labs CubeSat and STAIR fusion data. Remote Sensing of Environment, [s.1.], v. 239, p. 111615-111627, Mar 2020. DOI. 10.1016/j.rse.2019.111615.

MERCIER, A.; BETBEDER, J.; BAUDRY, J.; LE ROUX, V.; SPICHER, F.; LACOUX, J.; ROGER, D.; HUBERT-MOY, L. Evaluation of Sentinel-1 \& 2 time series for predicting wheat and rapeseed phenological stages. ISPRS Journal of Photogrammetry and Remote Sensing, [s.1.], v. 163, p. 231256, Mar 2020. DOI. 10.1016/j.isprsjprs.2020.03.009.

YANG, S.; BAI, J.; ZHAO, C.; LOU, H.; ZHANG, C.; GUAN, Y.; ZHANG, Y.; WANG, Z.; YU, X. The assessment of the changes of biomass and riparian buffer width in the terminal reservoir under the impact of the South-to-North water diversion project in China. Ecol. Indic., Coimbra, v. 85, n.1, p.932-943, Feb 2018. DOI. 10.1016/j.ecolind.2017.11.011. 